\title{
ISBT 128 Standard for Coding Medical Products of Human Origin
}

\author{
Paul Ashford Matthew Delgado \\ ICCBBA, San Bernadino, CA, USA
}

\section{Keywords}

Labeling · Standardization · Traceability . Transplantation

\section{Summary}

Background: ISBT 128 is an international standard for the terminology, coding, labeling, and identification of medical products of human origin (MPHO). Full implementation of ISBT 128 improves traceability, transparency, vigilance and surveillance, and interoperability. Methods: ICCBBA maintains the ISBT 128 standard through the activities of a network of expert volunteers, including representatives from professional scientific societies, governments and users, to standardize and maintain MPHO identification. These individuals are organized into Technical Advisory Groups and work within a structured framework as part of a quality-controlled standards development process. Results: The extensive involvement of international scientific and professional societies in the development of the standard has ensured that ISBT 128 has gained widespread recognition. The user community has developed confidence in the ability of the standard to adapt to new developments in their fields of interest. The standard is fully compatible with Single European Code requirements for tissues and cells and is utilized by many European tissue establishments. ISBT 128's flexibility and robustness has allowed for expansions into subject areas such as cellular therapy, regenerative medicine, and tissue banking. Conclusion: ISBT 128 is the internationally recognized standard for coding MPHO and has gained widespread use globally throughout the past two decades.

(c) 2017 S. Karger GmbH, Freiburg

\section{The Need for Traceability}

Since 2010, the World Health Organization (WHO) has urged member states 'to encourage the implementation of globally consistent coding systems for human cells, tissues, and organs as such in order to facilitate national and international traceability of materials of human origin for transplantation' [1]. Since then, WHO has broadened the scope of medical products of human origin (MPHO) to include blood, organs, bone marrow, cord blood, corneas, tissues, reproductive cells, and human milk. These MPHO are unique in that they are predominantly donated, difficult to replace, carry risks associated with disease transmission, and may be distributed globally.

The safety of MPHO is enhanced by effective systems of traceability, transparency, vigilance, and surveillance [2]. In order to meet the special traceability requirements of MPHO, consistent coding systems offer benefits when the following four elements are combined; globally unique identification, the ability to identify source organizations, globally agreed product terminology, and standardized mechanisms for electronic information transfer.

The ISBT 128 international standard for blood and transplants meets the four elements for consistent coding systems and has built upon these elements to create a flexible and stable standard. 21 scientific professional societies endorse ISBT 128, with some requiring use of ISBT 128 in their accreditation standards. These societies come from the fields of blood transfusion, cellular therapy, eye banking, tissue banking, and human milk banking.

\section{Development of the ISBT 128 Standard}

ISBT 128 was originally developed for use in blood transfusion to address safety concerns identified in field transfusion activities during the First Gulf War, including the misidentification of units arising from a lack of standardization and misunderstandings associated with language differences. The objective was to provide 


\begin{tabular}{ll}
\hline TAG Name & TAG Type \\
\hline APTAG - Asia Pacific TAG & Regional Blood Transfusion \\
ARTTAG - Assisted Reproductive Technology TAG & International Assisted Reproductive Technology \\
ATAG - Americas TAG & Regional Blood Transfusion \\
CTCLAG - Cellular Therapy Coding and Labeling & International Cellular Therapy \\
EBTAG - Eye Banking TAG & International Ocular Tissue Banking \\
EMATAG - Europe, Middle East, and Africa TAG & Regional Blood Transfusion \\
ETTAG - European Tissue TAG & Regional Tissue Banking \\
ITTAG - International Tissue TAG & International Tissue Banking \\
MBTAG- Milk Banking TAG & International Human Milk Banking \\
NATTAG & Regional Tissue Banking \\
RMTAG & International Regenerative Medicine \\
\hline
\end{tabular}

globally unique donation identification, standardized terminology and coding for product descriptions, and a globally standardized approach to the coding and decoding of information. This would eliminate the possibility of duplication of identifiers, reduce the risk of misunderstanding, and provide a highly reliable means of transferring information.

By 1994, the first version of the standard was produced and approved by the International Society of Blood Transfusion. One year later, ICCBBA was created as a not-for-profit custodian of the standard [3].

Adoption of ISBT 128 by the international blood transfusion community grew steadily, and by 2000 the cellular therapy and tissue banking fields, recognizing the success of ISBT 128, turned to ICCBBA to expand the standard into their areas of activity. Standardized terminology for cellular therapy [4] and eye banking [5] was developed in collaboration with relevant professional societies. In 2013, ICCBBA introduced terminology for organs as a result of the Standardization of Organ Nomenclature Globally (SONG) Project established by the WHO [6]. Today, ISBT 128 is able to provide standardized coding for all MPHO.

\section{Maintenance of the ISBT 128 Standard}

International standards need to be managed in a robust and transparent manner. ICCBBA manages the ISBT 128 standard within a controlled document management system as part of an ISO 9001:2015 accredited quality system. This system ensures that the standard remains stable, changes are thoroughly reviewed and approved, and backward compatibility is maintained.

ICCBBA has a small staff but is strongly supported by a network of over 250 active volunteer experts worldwide to provide input into the maintenance of the standard. These volunteers come from broad backgrounds including users, regulatory bodies, and government and supra-government organizations. This high level of support from professionals across all areas of MPHO ensures that the ISBT 128 standard addresses the constantly developing needs of these complex fields in a timely and effective manner.

ICCBBA organizes these volunteers into Technical Advisory Groups (TAGs) that each focus on a particular subject area. Com- prised of ICCBBA stakeholders, they are charged with providing input to the continued development and maintenance of the standard, and to provide educational and technical support to facilities implementing ISBT 128.

In order to ensure uniform policies across each TAG, Chairs are elected from each group. These Chairs, along with ICCBBA liaisons and members selected for their knowledge of the practical application of ISBT 128, form the ICCBBA Standards Committee. Responsibilities of the Standards Committee include reviewing publications prior to release and determining which TAG(s) will address specific technical issues.

There are currently 11 regional or international TAGs based on various subject areas, including blood, cellular therapy, regenerative medicine, reproductive tissue banking, tissue banking, ocular tissue banking, and milk banking. Participating in dozens of conference calls per year, volunteers have contributed to the development of standardized terminology and have advised on ways to shape the future of identification for hundreds of MPHO. The TAGs are listed in table 1.

When a change to the standard is requested, a transparent proposal process is used. For convenience, an electronic ISBT 128 standard proposal request form is available to registered users on the ICCBBA website. These proposals are reviewed by ICCBBA staff, relevant TAGs, and the Standards Committee. The status of each proposal can be viewed online at any time by registered users. Alternatively, status updates can be requested via the ICCBBA help desk. Over 50 archived proposals since 2009 can be viewed online by registered users. Updates to standards documents are posted for public comment prior to being published. This consultative approach assures that the standard is developed to best suit stakeholder needs.

In addition to internationally standardized terminology, ICCBBA is responsible for maintaining over 60 publications in connection with ISBT 128 , including standards documents, technical bulletins, joint publications, guidance and educational documents, and introductory materials. Staff are also responsible for maintaining and publishing regular updates to the Facility Identification Number Database, Product Description Code Database, and Issuing Organization Number Database (for use with World Marrow Association Registries). 
Table 2. Product description codes

\begin{tabular}{lll}
\hline PDC & Text & Interpretation \\
\hline V0202 & SCLERA|Left & Sclera from the left eye \\
V0222 & SCLERA|Left|Hypothermic storage|Ethanol|Whole & Whole sclera from the left eye, stored in ethanol at $2-8^{\circ} \mathrm{C}$ \\
\hline
\end{tabular}

ICCBBA provides a dedicated help desk run by experienced information specialists allowing ISBT 128 users to have their queries rapidly addressed. Help desk performance is monitored to ensure a high degree of stakeholder satisfaction.

\section{Product Coding - Tissues and Cells}

Product coding is based on the Information Environment Model [7]. Product codes are built up from the definitions of the standard terminology by combining terms into distinct product descriptions. The standardized terminology is based on the concepts of classes and attributes. The class describes the product at the most generic level. Additional product information can be added by selecting appropriate attribute variables to provide a unique product description at the level of detail desired by the user. Each product description is then assigned a unique code. This code, along with the type of collection and the division code, combine to form a product code. The product code is what is encoded within a standard bar code and printed on the label of cell therapy and tissue products. The product code allows individual divisions (splits) of a product to be distinctly identified by the use of a division code.

Of the ISBT 128 product description codes in the database, about $25 \%$, or 3,000 , are dedicated to cell therapy and tissue products, including ocular and reproductive tissue. The product description code is versatile in that a user can choose the level of detail to include in the label based on the needs of their end users. For example, either of the two product description codes in table 2 can be used to describe the same product at the time of labeling.

If no product code exists to correctly describe an MPHO, a request can be initiated using an online form submission. Requests will be reviewed and new product description codes assigned as appropriate. In some cases a request will require new classes, attribute groups, or attribute variables, and these will be reviewed by the appropriate TAG prior to being added to the terminology. Changes are published once approvals have been obtained, and users are notified. ICCBBA strives to process requests for new codes in a timely manner to meet user needs.

\section{Globalization of ISBT 128 for Cells and Tissues}

\section{Cellular Therapy}

The first facilities began utilizing ISBT 128 for cellular therapy in the late 1990s. Due to the nature of how and where these products are used, often crossing national borders, broad international consensus on standardization is essential [8]. Use of ISBT 128 for cellular therapy products has been globalized with input from or- ganizations such as: AABB, American Society for Blood and Marrow Transplantation, American Society for Apheresis, Asia Pacific Blood and Marrow Transplant, European Group for Blood and Marrow Transplantation, Foundation for the Accreditation of Cellular Therapy, International Society of Blood Transfusion, International Society for Cellular Therapy, Joint Accreditation Committee of ISCT and EBMT, National Marrow Donor Program, and the World Marrow Donor Association. To date, three international accreditation organizations require use of ISBT 128 terminology for cellular therapy products and a plan for full implementation of ISBT 128 coding.

\section{Eye Banking}

In 2010 ICCBBA met with the major eye banking professional associations and established an advisory group to develop a standardized approach to the terminology, coding, and labeling of ocular tissue. Participating associations were the Asia Cornea Society, the European Eye Banking Association, the Eye Bank Association of America, the Eye Bank Association of Australia and New Zealand, the Eye Bank Association of India, and the Pan American Association of Eye Banks. The terminology developed was published in 2013 [5]. The participating associations have adopted a consensus statement calling on eye banks globally to adopt the ISBT 128 standard for the coding and labeling of ocular tissue grafts. The Eye Bank Association of America requires the utilization of ISBT 128 identifiers on all ocular tissue distributed for surgical use.

\section{Assisted Reproduction Technologies (ART)}

A new initiative is under way to establish an internationally standardized terminology for reproductive tissue. This work is being performed by the ART Technical Advisory Group which includes representatives of the European Society for Human Reproduction and Embryology, the American Society for Reproductive Medicine, and the American Association of Tissue Banks.

\section{Other Tissues}

Many tissue banks preparing musculoskeletal, cardiovascular, and other tissue products have adopted ISBT 128 coding and labeling. The system is fully compatible with the Single European Code used in the European Union, and is also an accepted coding system for medical devices containing human cell and tissue products in the US. ISBT 128 terminology for these tissues has been developed through an international consultative process involving relevant scientific and professional bodies. An international tissue TAG with representatives from the American Association of Tissue Banks, the Asia Pacific Association of Surgical Tissue Banks, the Biotherapeutics Association of Australasia, and the European Tissue Banking Association has recently been formed. 


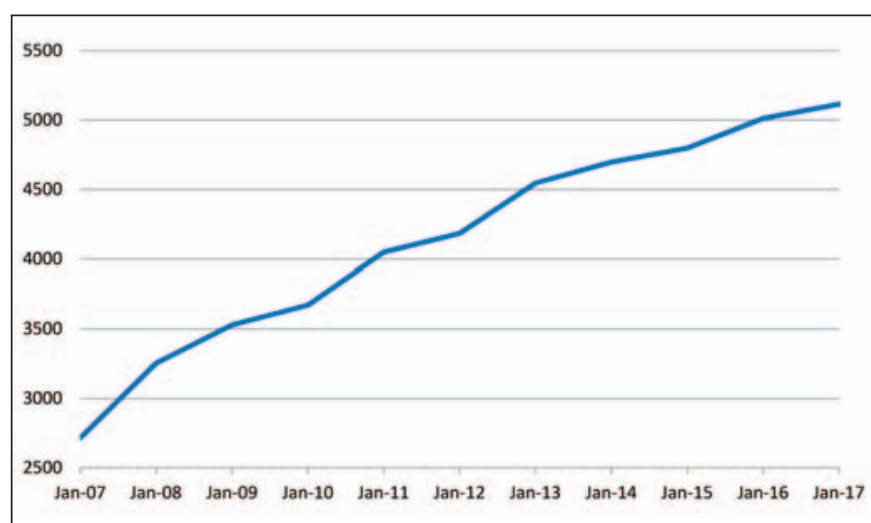

Fig. 1. ISBT 128-registered facilities.

\section{Regenerative Medicine}

Recognizing new developments in the field of regenerative medicine (i.e., regenerated tissues and seeded scaffolds), ICCBBA has taken steps to broaden the scope of ISBT 128. The Regenerative Medicine Technical Advisory Group has been formed and tasked with developing terminology in this field. The group is also discussing the coding of international nonproprietary names and US adopted name terminologies for cellular therapy in order to bring harmonization between product naming conventions.

\section{Worldwide Usage of ISBT 128}

As of May 2017 more than 5,000 facilities are licensed to use ISBT 128. These facilities are located in 86 nations around the world. It is estimated that over 40 million MPHO are labeled with ISBT 128 per year. This number continues to grow as the number of licensed facilities increases (see fig. 1).

\section{Information Access}

ICCBBA is constantly working to keep the ISBT 128 standard updated and to inform its users of any updates or developments. To facilitate this information transfer, ICCBBA utilizes a website that houses all relevant information. In addition to publications, the website contains presentations, frequently asked questions, TAG and Board of Director membership, fee information, databases, and several other resources, including videos. Additionally, ICCBBA provides a product lookup program to help in selecting the proper product description codes and tools for building a unique device identifier, and a Single European Code identifier.

Due to the complexity associated with introduction of a new labeling standard, ICCBBA offers a help desk to assist users and potential users with inquires relating to ISBT 128. Any technical, administrative, or general questions can be sent to iccba@iccbba. org. Most submissions are answered within 48 US business hours.

\section{Future}

MPHO is a broad term that encompasses several different subject areas in the medical field. As medicine continues to evolve, so will the ISBT 128 standard. Developments are continuously underway to address new MPHO products, support current MPHO products, and to adapt to changes in technology, coding, and information needs.

ICCBBA has designed the ISBT 128 standard in such a way that changes can be readily accommodated through a transparent and structured process.

Current projects include:

- A new international TAG for reproductive tissue

- A new international TAG for tissue products (non-ocular, nonreproductive) to supplement the activities of existing regional TAGs

- Documentation to support the use of ISBT 128 with organ transplant

- Interactive auditing tools for cellular therapy products

- The Global Registration Identifier for Donors for use by cellular therapy donor registries

- Use of ISBT 128 labeling for clinical trials.

While each new subject area or regulation is a unique challenge for ICCBBA, the ISBT 128 standard has proven itself to be stable and readily adaptable to change. Although significant progress has been made in some subject areas, particularly in blood transfusion and cellular therapy, there is much to consider in other subject areas.

For these new subject areas to flourish, it is essential to garner support from stakeholders around the world. Continued expert input and professional support are key to maintaining a balanced, robust, and internationalized standard. In addition, ICCBBA takes into account innovations in information transfer that could impact the future of how products are identified. Such potential developments include radio frequency identification (RFID) and 2D barcodes.

\section{FEES}

In order to maintain, develop, and provide ancillary services for ISBT 128 , ICCBBA charges an annual licensing fee for registered users. Registered users include facilities that use ISBT 128 identification and vendors that supply ISBT 128-compliant software, equipment, applications, supplies, and consultancy services.

Each year, the annual licensing fee is established by the Board of Directors according to a schedule that indexes several factors. This is done to ensure that fees are maintained as low as possible while ensuring that expenditures needed to operate the organization are met: a practice required to maintain not for profit status. Key factors in calculating the licensing fee include the type of licensee organization, the subject area, and the international location of the organization in accordance with the United Nation's Human Development Index. If a facility is located in a low or medium Human Development Index country, ICCBBA offers percentage reductions in annual fees of $66 \%$ and $33 \%$, respectively. Users and prospective users are encouraged to visit the ICCBBA website for the most up-to-date fee schedules. 


\section{ICCBBA}

ISBT 128 is managed by ICCBBA, a nongovernmental organization in official relations with WHO.

ICCBBA is governed by an international volunteer Board of Directors comprising leaders in the fields of blood transfusion, cellular therapy, tissue banking, ocular tissue banking, organ transplantation and regenerative medicine. The Board of Directors meets regularly through conference calls and an annual face to face meeting.

ICCBBA is a tax exempt, nonprofit organization as described in Section 501 (c)(3) of the US Internal Revenue Code (Internal Revenue Service 2017). These regulations stipulate that the organization cannot be organized or operated for the benefit of private interests, and no part of the organization's net earnings may inure to the benefit of any private shareholder or individual (IRS.gov 2017). Within its articles of association, ICCBBA is required to be organized and operated exclusively for charitable, scientific, and educational purposes. Annual reports of the organizations finances can be found on the ICCBBA website at www.iccbba.org.

\section{Disclosure Statement}

P. Ashford is the Executive Director and M. Delgado is the Global Development Director of ICCBBA. Both authors receive compensation from ICCBBA in their respective roles. There are no other conflicts of interest to disclose.

\section{References}

1 Resolution WHA63.22. Human organ and tissue transplantation. Sixty-third World Health Assembly, Geneva, 17-21 May 2010. Volume 1. Resolutions and decisions. Geneva: World Health Organization; 2010 (WHA63/2010/REC/1). http://apps.who.int/ gb/ebwha/pdf_files/WHA63/A63_R22-en.pdf(last accessed November 6, 2017).

2 Strong DM, Shinozaki N: Coding and traceability for cells, tissues and organs for transplantation. Cell Tissue Bank 2010;11:305-323.

3 Steane EA, Steane SM: Closing the loop: standardization is the key. Transfusion 1996; 36:200-202.

4 Ashford P, Distler P, Gee A, Lankester A, Larsson S, Feller I, Loper K, Pamphilon D, Poston L, Rabe F, Slaper-Cortenbach I, Szczepiorkowski Z, Warkentin P: Standards for the terminology and labeling of cellular therapy products. Transfusion 2007;47:13191327.

5 Armitage WJ, Ashford P, Crow B, Dahl P, DeMatteo MCM, Distler P, Gopinathan U, Madden PW, Mannis MJ, Moffatt SL, Ponzin D, Tan D: Standard terminology and labeling of ocular tissue for transplantation. Cornea 2013;32:725-728.

6 WHO Standard Organ Transplant Nomenclature, Version 1. World Health Organization. www.who.int/entity/patientsafety/WHO-Standard-Organ-TransplantNomenclature-1-0.pdf (last accessed November 6, 2017).

7 Ashford PR: ISBT 128: contributing to the safety of transfusion and transplantation. ISBT Sci Ser 2007;2:113-116.

8 Slaper I: ISBT 128 coding and labeling for cellular therapy products. Cell Tissue Bank 2010;11:375-378. 